\section{Discurso da pessoa vulnerada pós-avc: possibilidades bioéticas}

\section{Batista, Marcos Antonio}

Universidade do Vale do Sapucaí - Univás, Pouso Alegre $M G$

\section{Reis, Rogério Donizeti}

Universidade do Vale do Sapucaí - Univás, Pouso Alegre MG e-mail: rogerioreisfisio@yahoo.com.br

PALAVRAS-CHAVE: AVC, Idoso, Vulnerabilidade, Bioética

Introdução - Para Pessini ser vulnerável é ser frágil, ser suscetível de ser ferido e sofrer. Esta fragilidade é uma condição natural da humanidade, um "aspecto inevitável e permanente da nossa condição humana". A vulnerabilidade surge de nossa condição humana, a partir da possibilidade do corpo humano ser ferido e da inevitabilidade da fragilidade da velhice e da morte. Por outro lado, a vulnerabilidade corporal liga-se a natureza social da vida humana. Como seres sociais, somos vulneráveis às ações dos outros e dependentes do cuidado e apoio dos outros, em graus diversos e em vários momentos de nossas vidas. As pessoas precisam, em maior ou menor grau, e em diferentes estágios da vida, do cuidado alheio, o que as torna intrinsecamente vulneráveis. Estar em uma situação de vulneração leva a uma dependência mútua do cuidador e do ser que recebe os cuidados, instituído assim, além de responsabilidades, também elementos de reciprocidade, solidariedade, confiança e cooperação. O processo de vulnerabilidade é uma situação inerente ao ciclo da vida humana. Refletindo com base na bioética todos os seres vulnerados necessitam de proteção e os idosos diante de uma doença crônica como AVC ficam na dependência de cuidados alheios, pois suas condições de autocuidado e de autonomia são limitados ou praticamente ausentes. De fato, o AVC tem um grande potencial para gerar déficit no funcionamento físico, sensorial e cognitivo, com impacto no dia-a-dia e desempenho do indivíduo no que diz respeito às atividades de vida diária. Objetivo - Conhecer as realidades de vidas de idosos alteradas por um AVC. Método - Tratou-se de uma pesquisa com delineamento qualitativo, quantitativo e analítico, os dados foram analisadas pelo software Iramuteq. Resultados - As classes agrupadas emergentes do tema "Percepção de vida dos idosos antes e depois do AVC" foram: "Dependencia física, "Tomada de consciência antes e pós o AVC", "Isolamento social", Vulnerabilidade da vida humana" e "Cuidar e ser cuidado". Conclusão: As análises dos resultados por meio do Software permitiu conhecer com clareza e profundidade o quanto o vulnerado por um AVC tem sua dignidade comprometida revelando as várias facetas da vulnerabilidade. Vulnerabilidade esta complexa para se definir que se torna fácil de compreender prisma e discurso do vulnerado. Este trabalho foi aprovado pelo CEP da Fundação de Ensino Superior do Vale do Sapucaí pelo CAAE: 80873617.3.0000.5102.

\section{REFERÊNCIAS}

[1] PESSINI, L. Elementos para uma bioética global: solidariedade, vulnerabilidade e precaução. Thaumazein: Revista Online de Filosofia, Santa Maria, Ano VII, v. 10, n. 19, p. 75-85, 2017. 